\title{
Syntactic priming and the lexical boost effect during sentence production and sentence comprehension: An fMRI study
}

\author{
Katrien Segaert ${ }^{\mathrm{a}, \mathrm{b}, *}$, Gerard Kempen ${ }^{\mathrm{a}, \mathrm{c}}$, Karl Magnus Petersson ${ }^{\mathrm{a}, \mathrm{b}}$, Peter Hagoort ${ }^{\mathrm{a}, \mathrm{b}}$ \\ ${ }^{a}$ Max Planck Institute for Psycholinguistics, Nijmegen, The Netherlands \\ ${ }^{\mathrm{b}}$ Radboud University Nijmegen, Donders Institute for Brain, Cognition and Behaviour, Centre for Cognitive Neuroimaging, Nijmegen, The Netherlands \\ ${ }^{\mathrm{c}}$ Cognitive Psychology Unit, Leiden University, Leiden, The Netherlands
}

\section{A R T I C L E I N F O}

Article history:

Accepted 19 December 2012

\section{Keywords:}

Syntactic priming

Lexical boost effect

fMRI adaptation

Repetition suppression

Active and passive sentences

Lexical repetition

\begin{abstract}
A B S T R A C T
Behavioral syntactic priming effects during sentence comprehension are typically observed only if both the syntactic structure and lexical head are repeated. In contrast, during production syntactic priming occurs with structure repetition alone, but the effect is boosted by repetition of the lexical head. We used fMRI to investigate the neuronal correlates of syntactic priming and lexical boost effects during sentence production and comprehension. The critical measure was the magnitude of fMRI adaptation to repetition of sentences in active or passive voice, with or without verb repetition. In conditions with repeated verbs, we observed adaptation to structure repetition in the left IFG and MTG, for active and passive voice. However, in the absence of repeated verbs, adaptation occurred only for passive sentences. None of the fMRI adaptation effects yielded differential effects for production versus comprehension, suggesting that sentence comprehension and production are subserved by the same neuronal infrastructure for syntactic processing.
\end{abstract}

(c) 2013 Elsevier Inc. All rights reserved.

\section{Introduction}

Syntactic priming refers to facilitation of syntactic processing when a syntactic structure is repeated across consecutive sentences (Bock, 1986; Kempen, 1977; Levelt, 1989). Syntactic priming is also called "structural priming"; and, given a pair of consecutive sentences, the first is called "prime", the second "target". During sentence production tasks, the facilitation manifests itself in an increased tendency for speakers to repeat, in the target utterance, aspects of the syntactic structure of a perceived or selfproduced prime sentence, or in a reduction of the amount of processing resources recruited to produce the target. During sentence comprehension tasks, priming becomes manifest in a reduction of the resources needed to process the target sentence. Numerous behavioral studies have reported syntactic priming effects, during sentence production and sentence comprehension. During production, syntactic priming is reflected in an increased likelihood to choose, for instance, the same grammatical voice (active versus passive) or the same type of dative construction (double-object versus prepositional dative) in consecutive sentences (e.g. Bock, 1986; Bock \& Loebell, 1990) or in faster speech onsets for repeated syntactic structures (Corley \& Scheepers, 2002; Segaert, Menenti,

* Corresponding author at: Max Planck Institute for Psycholinguistics, P.O. Box 310, NL-6500 AH Nijmegen, The Netherlands. Fax: +31 243521213.

E-mail address: Katrien.Segaert@mpi.nl (K. Segaert).
Weber, \& Hagoort, 2011; Smith \& Wheeldon, 2001; Wheeldon \& Smith, 2003; Wheeldon, Smith, \& Apperly, 2011). Syntactic priming in comprehension is shown in anticipatory eye-movements to pictures (Arai, van Gompel, \& Scheepers, 2007; Carminati, van Gompel, Scheepers, \& Arai, 2008; Thothathiri \& Snedeker, 2008a; Traxler, 2008), in faster reading (Traxler \& Tooley, 2008) and in picture-matching choices for ambiguous phrases (Branigan, Pickering, \& McLean, 2005). In comprehension tasks, ERP studies revealed the attenuation of the $\mathrm{P} 600$ amplitude as a result of syntactic priming (Ledoux, Traxler, \& Swaab, 2007; Tooley, Traxler, \& Swaab, 2009).

A crucial observation is that syntactic priming effects are sometimes amplified when not only the syntactic structure is repeated but also the lexical head of this structure (Pickering \& Branigan, 1998). This syntactic priming phenomenon is known as the "lexical boost effect". However, the magnitude of the effect tends to vary in function of modality (production versus comprehension). Studies on sentence production found that syntactic priming effects occur in the absence of lexical repetition and are boosted when the head word is repeated (e.g. Branigan, Pickering, \& Cleland, 2000; Corley \& Scheepers, 2002; Hartsuiker, Bernolet, Schoonbaert, Speybroeck, \& Vanderelst, 2008; Pickering \& Branigan, 1998; Segaert et al., 2011; Wheeldon et al., 2011). In contrast, studies of syntactic priming and the lexical boost effect during sentence comprehension reveal a somewhat different picture. Syntactic priming in comprehension seems to be dependent on repetition of the head-word (usually a verb: Arai et al., 2007; Branigan et al., 
2005; Carminati et al., 2008; Ledoux et al., 2007; Tooley et al., 2009; Traxler \& Tooley, 2007). Strikingly, so far only three comprehension studies reported syntactic priming independent from verb repetition (Thothathiri \& Snedeker, 2008a,b; Traxler, 2008). The overall picture emerging from behavioral and ERP research shows syntactic priming during comprehension only in conditions of verb repetition, whereas during production syntactic priming also occurs in the absence of verb repetition.

As regards the cognitive mechanisms underlying syntactic priming and the lexical boost, two proposals have gained prominence in the psycholinguistic literature (Ferreira \& Bock, 2006; Pickering \& Ferreira, 2008). One proposal holds that syntactic priming is due to implicit learning of a syntactic structure building process (Bock \& Loebell, 1990; Chang, Dell, \& Bock, 2006; Chang, Dell, Bock, \& Griffin, 2000). In this account, lexical processing occurs independently of syntactic processing (Chang, 2002; Chang et al., 2000, 2006). Therefore, syntactic priming effects can be observed in the absence of lexical overlap between prime and target structures. The lexical boost is due to explicit memory: Repetition of a lexical item in the target leads to reactivation of the memory trace of that item in the prime sentence, and thereby to reactivation of the prime's syntactic structure (Bock \& Griffin, 2000). Implicit learning is proposed as syntactic priming mechanism for comprehension as well as production (Bock, Dell, Chang, \& Onishi, 2007). According to the second proposal, syntactic priming is a consequence of residual activation left behind after the prime sentence has been processed (Cleland \& Pickering, 2003; Pickering \& Branigan, 1998). This activation causes the target sentence to be processed in a manner similar to the way the prime was processed. For instance, if the target is a transitive clause that can be processed with either active or passive voice, then residual activation left by a passive prime will bias the target towards adopting passive voice as well. Repetition of the head-word across prime and target means that an extra portion of the prime's residual activation is mounted during target processing, with a stronger bias as a result. Given that the relevant represented information about syntactic forms is the same in comprehension and production, residual activation is proposed as syntactic priming mechanism for comprehension and production (Pickering \& Branigan, 1999).

What could be the cause of the differential effects of syntactic priming and the lexical boost on the production and comprehension modalities? One possibility is the involvement of different syntactic processing mechanisms underlying the modalities. However, before exploring this theoretical avenue, we first need to rule out explanations based on differences between the experimental tasks carried out by the participants in comprehension versus production tasks. Syntactic priming in comprehension is usually measured through eye movements, reading times, or aspects of EEG signals. On the other hand, syntactic priming in production is usually measured in terms of syntactic choices or production speed (response onset latencies). Additionally, the sentence materials presented or produced in the two modalities tends to be rather different-typically more complex in comprehension than in production tasks. While comparable behavioral measures of syntactic priming and lexical boost effects in production and comprehension might prove difficult to obtain, fMRI provides an obvious standard of comparison: Changes in the neuronal activity in response to syntactic and lexical priming manipulations can be measured in either modality. To our knowledge, no such measurements have been carried out to date.

Numerous neuroimaging studies have investigated the brain regions involved in syntactic processing in the two modalities. They reveal that the left inferior frontal and left posterior temporal regions are implicated in syntactic processing in comprehension (e.g. Cooke et al., 2006; Embick, Marantz, Miyashita, O’Neil, \& Sakai, 2000; Fiebach, Schlesewsky, Lohmann, von Cramon, \& Friederici, 2005; Ni et al., 2000; Snijders et al., 2009; Vigneau et al., 2006; see Indefrey, 2012a,b for a review). Far fewer neuroimaging studies have looked at sentence production. They show that left inferior frontal regions (Haller, Radue, Erb, Grodd, \& Kircher, 2005; Indefrey, Hellwig, Herzog, Seitz, \& Hagoort, 2004; Indefrey et al., 2001; Peck et al., 2004) and sometimes also left posterior temporal regions (Menenti, Segaert, \& Hagoort, 2012) are implicated in syntactic processing in production. In our own recent work aiming to compare the brain regions involved in comprehension and production, we found that syntactic processing in the two modalities is subserved by largely the same brain regions-the left IFG and left posterior MTG (Menenti, Gierhan, Segaert, \& Hagoort, 2011; Segaert, Menenti, Weber, Petersson, \& Hagoort, 2012). Some neuroimaging studies implicate these regions in lexical processing as well (Keller, Carpenter, \& Just, 2001; Menenti et al., 2011; Newman, Ratliff, Muratore, \& Burns, 2009), making them ideal candidates for interactions between syntactic and lexical processing.

The available neuroimaging findings even suggest a specific division of labor between the left IFG and the left MTG. During syntactic processing, the left MTG supports the retrieval of lexical-syntactic information from long-term memory, while the left IFG supports the unification of this information into syntactic sentence-level representations (Hagoort, 2003, 2005; Snijders et al., 2009).

Some neuroimaging studies have focused on the neuronal correlates of syntactic priming (Devauchelle, Oppenheim, Rizzi, Dehaene, \& Pallier, 2009; Menenti, Segaert, \& Hagoort, 2012; Menenti et al., 2011; Noppeney \& Price, 2004; Segaert et al., 2012; Weber \& Indefrey, 2009). In fMRI, syntactic priming manifests itself through adaptation. fMRI adaptation is a phenomenon whereby the BOLDresponse in areas sensitive to a stimulus property, for example a syntactic property, is reduced or enhanced when this stimulus property is repeated (Henson, 2003; Segaert, Weber, de Lange, Petersson, \& Hagoort, 2013). Repetition suppression has been demonstrated for syntactic priming of sentence comprehension as well as production (Menenti et al., 2011, 2012; Noppeney \& Price, 2004; Segaert et al., 2012; Weber \& Indefrey, 2009).

In the event-related fMRI study reported below, we investigated the neuronal correlates of syntactic priming and lexical boost effects, during sentence production and comprehension. As far as we know, this is the first study to directly compare the effects of syntactic priming and the lexical boost on neuronal activity in both language processing modalities. We measured the extent of fMRI adaptation to repetition of verb-headed syntactic constructions (clauses in active or passive voice) with versus without repetition of the head verb. fMRI adaptation of neuronal activity serves as a method to compare the effects of syntactic priming and the lexical boost during production and comprehension. We measured these effects during maximally similar sentence production and sentence comprehension tasks (same set of sentential structures, same stimulus materials, same temporal conditions, etc.). We expected to find syntactic priming and lexical boost effects in the left IFG and MTG. If the differential results for comprehension and production in behavioral and ERP studies are exclusively due to differences in methodological aspects of the measurement, then we expect the neuronal response to syntactic priming and the lexical boost in the two processing modalities to be comparable. Alternatively, if the said differential results reflect the involvement of different underlying (neuro)cognitive processing mechanisms, then we expect the fMRI results to mirror the behavioral and ERP results. In that case, we predict syntactic priming to occur during production in the absence of lexical repetition, while syntactic priming in comprehension will require verb repetition.

\section{Materials and methods}

The fMRI data for syntactic priming with verb repetition were collected before and have already been reported in Segaert et al. 
(2012). For the present report, we collected a new set of fMRI data on syntactic priming without verb repetition (while keeping other things maximally similar, in particular the testing procedure and fMRI data acquisition parameters). Below, we report a comparison between these new data and the dataset from Segaert et al. (2012), that is, a comparison between the Verb-Repetition and the NoVerb-Repetition levels of the Verb-Repetition factor.

\subsection{Participants}

Twenty-four right-handed native Dutch speakers without neurological or language impairments and with normal or correctedto-normal vision (12 male; mean age 21 years, SD 3.0) participated in the new experiment (i.e. the dataset on syntactic priming without verb repetition). Ten participants (five male; mean age 20 years SD 2.3) who had contributed to the Segaert et al. (2012) dataset were willing to re-participate in the new experiment (16 months later). ${ }^{1}$ The other fourteen participants had not participated before. All participants were university educated. Participants gave written informed consent prior to the experiment and were compensated for their participation.

\subsection{Stimulus material}

We investigated syntactic priming of active and passive voice clauses headed by transitive Dutch verbs. The stimulus material and task was first used by Menenti et al. (2011). There were 1728 photographs and 432 auditory sentence descriptions of transitive events. These depicted 36 different events such as kissing, helping or strangling with the agent and patient of this action (see Appendix). The patient of an event is the one who is acted on. Each event was enacted in the photographs by four pairs (twice man/ woman; twice boy/girl), each of these once with the male actor as agent and once with the female actor as agent. Each photograph also had one version with the agent on the left and one version with the agent on the right. Of each photograph depicting a transitive event, there were two color-coded versions and one grayscale version. Color-coded photographs elicited either active or passive sentence descriptions: participants were instructed to describe these photographs naming the green actor prior to the red actor. There was an active version with a green agent and a red patient, and a passive version with a red agent and a green patient. The two color-coded versions were used during production trials. During comprehension, we presented grayscale photographs (identical to the photographs used in the production trials) and the photographs were accompanied by auditory sentence descriptions of either active or passive syntactic structures. Passive syntactic structures in Dutch have (at least) two possible word orders (two different linearizations of the Dutch by-phrase). The more frequent word order places the by-phrase before the clause-final head verb (De vrouw wordt door de man gekust 'The woman is by the man kissed'); the less frequent word order places the by-phrase after the head verb (De vrouw wordt gekust door de man 'The woman is kissed by the man'). The auditory sentence descriptions for passive sentences used the more frequent word order.

There were also 795 photographs and 303 concomitant auditory sentence descriptions serving as fillers. These fillers depicted or described intransitive events such as singing and running or locative actions such as standing and lying. The intransitive photographs depicted one actor in green or in red for production trials, or one actor in grayscale (accompanied by an auditory description) for compre-

\footnotetext{
${ }^{1}$ We asked people to re-participate in order to have the possibility of testing whether the difference between the No-Verb-Repetition condition and the VerbRepetition condition could be due to differences between participants instead of differences due to the manipulation of Verb Repetition (see also footnote 4).
}

hension trials. The locative photographs depicted two objects, or one actor and one object. For production trials, there were two color-coded versions of the locatives serving to elicit a clause-final locative phrase (De bal ligt op de tafel 'The ball lies on the table') or a fronted locative phrase $(O p$ de tafel ligt de bal 'On the table lies the ball'). For comprehension trials, there was a grayscale version which would be accompanied by a clause-final locative phrase or a fronted-locative phrase. The intransitive and locative filler items lent variability to the syntactic structures and the lexical items that participants produced/heard during the experiment. For intransitives, the actors were sometimes famous people, animals, or people that could be named by their profession; for locatives, we used inanimate objects.

For the comprehension trials, there were also 97 auditory sentence descriptions that did not match the accompanying grayscale photograph. These mismatch trials were used for attention control. The descriptions were grammatically correct but did not describe the situation depicted in the photograph. There were mismatch descriptions of intransitive photographs (50\%) and of transitive photographs (50\%). Semantic and syntactic processing was necessary to be able to detect the mismatches between photograph and auditory description. For example, given a photograph that depicted a man kissing a woman, mismatch descriptions could be The man punishes the woman, The girl kisses the woman, The woman kisses the man. The transitive mismatch items did not belong to the target items. We pre-tested all materials in order to establish whether the depicted actions were clear, and to determine which verb was used most often to describe the action. This verb was presented preceding the photographs in the course of the actual experiment.

\subsection{Experimental design}

We used a $2 \times 2 \times 2 \times 2 \times 2$ design with the following withinsubjects factors: (1) voice of the target sentence (active or passive); (2) syntactic repetition (voice of the produced/heard clause in prime and target sentence was same or different); (3) processing modality of the prime (production/speaking or comprehension/listening); (4) processing modality of the target (production or comprehension). As between-subjects factor (5) we manipulated whether the head verbs of prime and target sentences were identical or different. ${ }^{2}$ This resulted in 32 conditions. The design is illustrated in Fig. 1. The syntactic priming effect is the main effect of syntactic repetition (i.e. the comparison of target trials using novel syntax with trials using repeated syntax). The lexical priming effect is the main effect of verb repetition (i.e. the comparison of target trials using novel verbs with target trials using repeated verbs). The lexical boost of syntactic priming is examined by testing the interaction between syntactic repetition and verb repetition.

Each participant received a list of items in either the Verb-Repetition Condition or the No-Verb-Repetition Condition. We used a running priming paradigm where each target item also served as the prime sentence for the next target item (Fig. 2). The target items were presented in 80 blocks with an average length of 5 transitive structures (range 3-7 items). The conditions followed each other in a random order that was different for every participant, with two constraints on the order of conditions: No condition was repeated twice in a row; and a target item with adults was always followed by a target item with children and vice versa, so that

\footnotetext{
${ }^{2}$ Verb Repetition, in fact, is partly a within-subjects and partly a between-subjects factor (see header 'Materials and Methods' and 'Participants'). Of course, it is not possible to analyze the data this way; so, we had to choose between considering Verb Repetition either as a within-subjects or a between-subjects factor. Within-subjects analyses are considerably less conservative because they do not attribute to subjects variance that in reality is due to subjects, hence yielding Type-I errors. Therefore, we chose the conservative option and treated Verb Repetition as a between-subjects factor.
} 


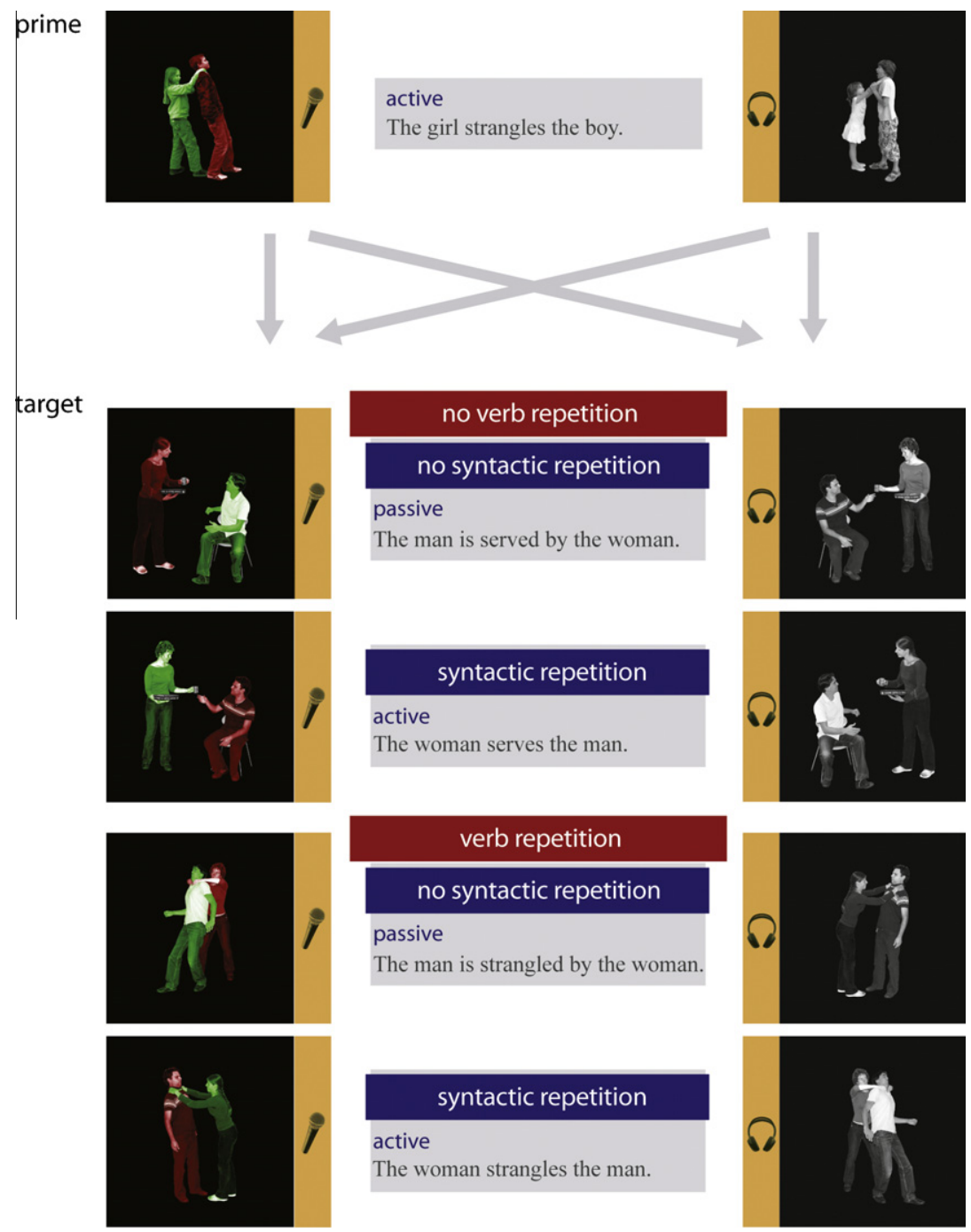

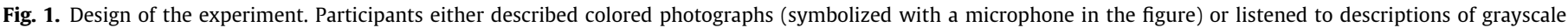

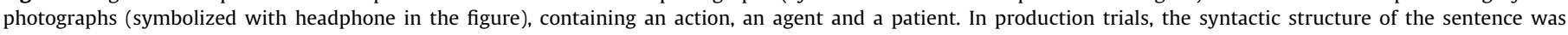

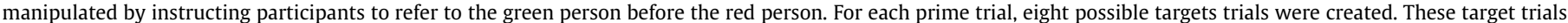

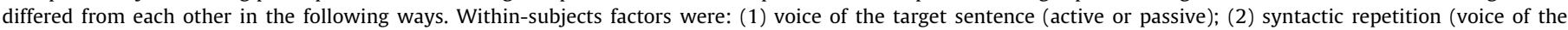

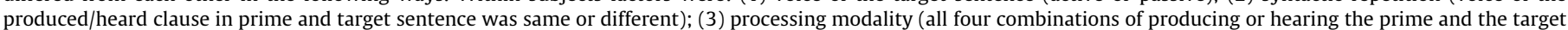

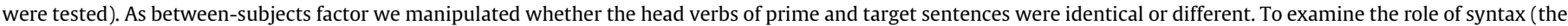

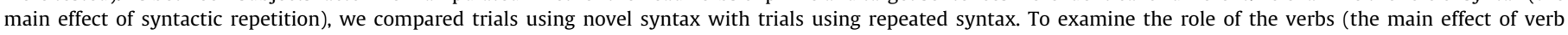

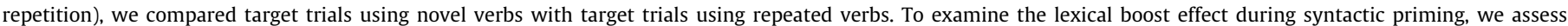
whether there is an interaction between syntactic repetition and verb repetition. Example words and sentences have been translated from Dutch.

in the lists with verb repetition there would be no lexical repetition other than repetition of the verb. The target blocks alternated with filler blocks with an average length of 3.5 (range 2-5 items). In the lists with verb repetition, the verb was always repeated in a target block and was mostly, but not always, repeated between the filler items in the filler block. For $10 \%$ of the filler items this was not the case, which served to bring in some extra variation. A full list of items presented to the participant consisted of approximately $59 \%$ transitive structures and $41 \%$ fillers. Fifty percent of the items were production items and $50 \%$ were comprehension items.

A full list of items contained the following elements. There were 20 items in each of the 16 conditions resulting from fully crossing the within-subjects factors. Additionally, in the beginning of each of the 80 blocks of transitive structure items, there was one transitive structure item serving as a prime-only item. This increased the number of transitive structure items to 400 . Each participant received 680 trials in total during a full lists of items (transitive and filler structures), which were distributed over two scanning runs with a break in between. In a full list of items presented to any participant, a certain action or a certain pair of actors could occur several times, but a certain combination of actors and action was presented only once. Every participant saw a different list of items.

\subsection{Task and procedure}

The stimuli were presented in the following way. First, the verb was shown (in citation form, i.e. the infinitive). Then followed a photograph, accompanied by an auditory description during comprehension trials only. The presented verb was color-coded to let the participant know whether a 'comprehension photograph' or a 'production photograph' would follow. Green verbs preceded colored production photographs and gray verbs preceded black/white comprehension photographs (Fig. 2). 


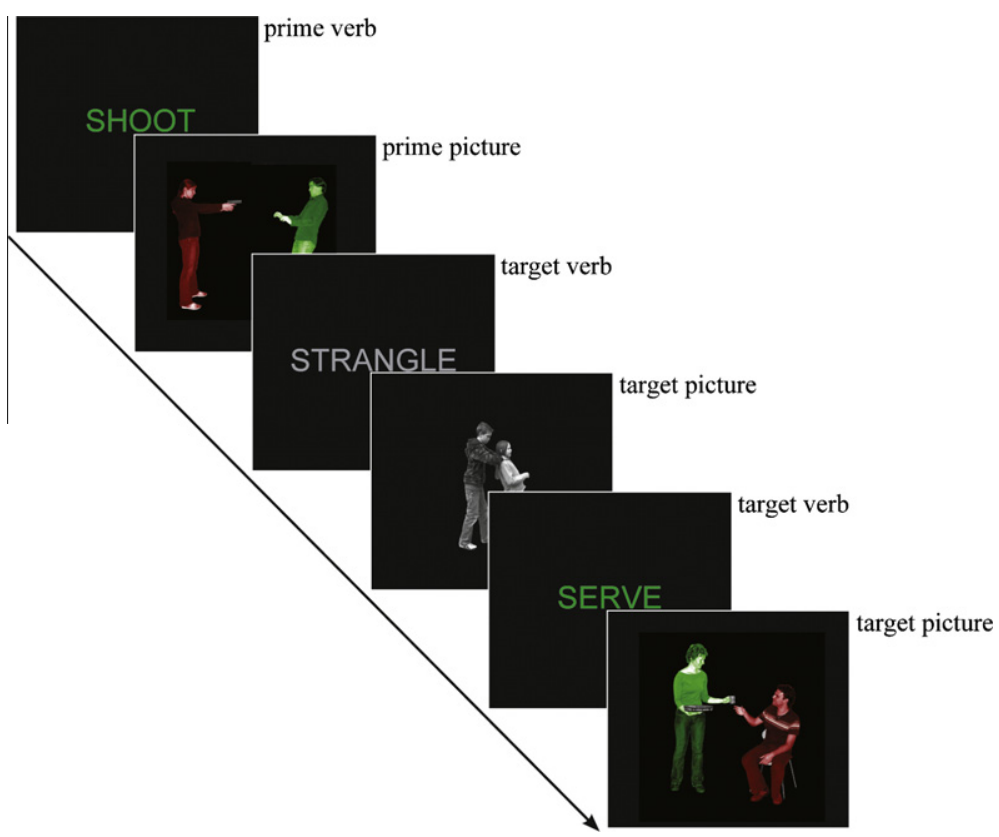

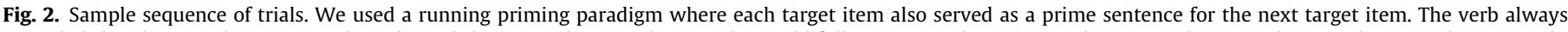

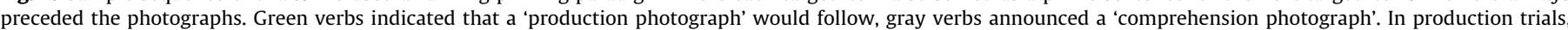

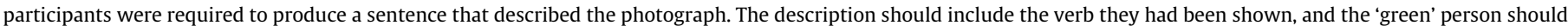

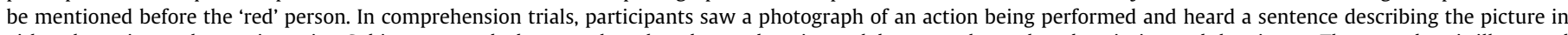

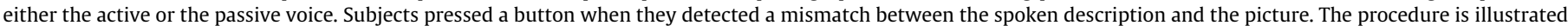
by a sequence of sentences in the condition without verb repetition.

\subsubsection{Production}

During production trials, the task was to describe the colorcoded photographs overtly with a short sentence that should include (a conjugated form of) the presented verb. Participants were instructed to name the green actor before the red actor (stoplight paradigm: Menenti et al., 2011). There was no cue for the participants to start the descriptions; they could freely start whenever they were ready.

\subsubsection{Comprehension}

During comprehension trials, we used a sentence-picture matching paradigm (Clark \& Chase, 1972): Participants were presented with a photograph and an auditory description. The photographs were the grayscale versions of the ones used in the production trials. This paradigm has been used extensively, and a recent study supports its suitability for studying online situated language comprehension (Knoeferle, Urbach, \& Kutas, 2011). By choosing situated paradigms for both production and comprehension trials, we maximize comparability and ensure that the difference between the two only lies in language processing. To force participants to pay attention, we instructed them to listen carefully to the description of the black/white photographs and use the response box to indicate when this description was incorrect (the response hand was counterbalanced between participants). During $10 \%$ of the comprehension trials there was a mismatch between the description and the photographs. Only for those trials a response had to be given.

Participants completed a short practice block in the scanner before the actual experiment started. The experiment consisted of two runs of $45 \mathrm{~min}$. Between the two runs, the participants were subjected to an anatomical T1 scan and had a short break outside the MRI-scanner. Each trial consisted of the following events. First, the verb was presented for $500 \mathrm{~ms}$. After an ISI of $500-2500 \mathrm{~ms}$, the photograph was presented for $2000 \mathrm{~ms}$, whereafter the screen turned black. The photograph thus had a fixed presentation time during production and comprehension trials. In comprehension trials, there was an ISI of $0-1000 \mathrm{~ms}$ between the photograph appearing on screen and the auditory sentence description, enabling us to differentiate between the onset of the photograph and the auditory description in our analyses. In production as well as comprehension trials, participants were free to start responding (i.e. to start speaking or to press the button to indicate mismatch) whenever they were ready. The total trial duration of one trial was $7000 \mathrm{~ms}$. The experimenter coded the participant's production responses online for correctness. Target trials were analyzed if during both prime and target trial (1) the correct structure was used and (2) both actors were named accurately and the verb was used correctly. (Examples of correct active and passive sentence descriptions are illustrated in Fig. 1.)

\section{5. fMRI data acquisition}

Participants were scanned with a Siemens 3T Tim-Trio MRIscanner, using a 12-channel surface coil. In order to acquire functional data we used parallel-acquired inhomogeneity-desensitized fMRI (Poser, Versluis, Hoogduin, \& Norris, 2006). This is a multiecho EPI sequence, in which images are acquired at multiple TE's following a single excitation $(\mathrm{TR}=2.398 \mathrm{~s}$; each volume consisted of 31 slices of $3 \mathrm{~mm}$ thickness with slice-gap of $17 \%$; isotropic voxel size $=3.5 \times 3.5 \times 3 \mathrm{~mm}^{3}$; field of view $=224 \mathrm{~mm}$ ). The functional images were acquired at following TE's: $\mathrm{TE}_{1}$ at $9.4 \mathrm{~ms}, \mathrm{TE}_{2}$ at $21.2 \mathrm{~ms}, \mathrm{TE}_{3}$ at $33 \mathrm{~ms}, \mathrm{TE}_{4}$ at $45 \mathrm{~ms}$, and $\mathrm{TE}_{5}$ at $56 \mathrm{~ms}$, with echo spacing of $0.5 \mathrm{~ms}$. This entails a broadened $T_{2}^{*}$ coverage, because $T_{2}^{*}$ mixes into the five echoes in a different way, and the estimate of $T_{2}^{*}$ is improved. Accelerated parallel imaging reduces image artifacts, hence is a suitable method to acquire data when participants are producing sentences in the scanner (thereby causing motion and susceptibility artifacts). However, the number of slices did not allow acquisition of a full brain volume in most participants. We made sure that the entire temporal and frontal lobes were scanned because these were the regions where the fMRI adaptation effects of interest were expected to occur. This meant that data from the 
superior posterior frontal lobe and the superior parietal lobe (that is, data from the top of the head) could not be obtained in several participants. A whole-brain high-resolution structural T1-weigthed MPRAGE sequence was performed to characterize participants' anatomy (TR $=2300 \mathrm{~ms}, \mathrm{TE}=3.03 \mathrm{~ms}, 192$ slices with voxel size of $\left.1 \mathrm{~mm}^{3}, F O V=256\right)$, accelerated with GRAPPA parallel imaging.

\subsection{Data analysis}

\subsubsection{Preprocessing}

fMRI data were preprocessed using SPM5 (Friston, Ashburner, Kiebel, Nichols, \& Penny, 2007). The first five images were discarded to allow for $T_{1}$ equilibration. Then the five echoes of the remaining images were realigned to correct for motion artifacts. Estimation of the realignment parameters was done for one echo and then copied to the other echoes. The five echoes were combined into one image using a method designed to filter task-correlated motion out of the signal (Buur, Poser, \& Norris, 2009). First, echoes two through five (i.e., $\mathrm{TE}_{2}, \mathrm{TE}_{3}, \mathrm{TE}_{4}$ and $\mathrm{TE}_{5}$ ) were combined using a weighting vector with weights depending on the measured differential contrast-to-noise ratio. The time course of an image acquired at a very short echo time $\left(\mathrm{TE}_{1}\right)$ was then used in a linear regression as a voxelwise regressor for the other image (i.e., the result of combining $\mathrm{TE}_{2}, \mathrm{TE}_{3}, \mathrm{TE}_{4}$ and $\mathrm{TE}_{5}$ ) in the same echo train acquired with high BOLD sensitivity. The resulting images were coregistered to the participants' anatomical volume, normalized to MNI space and spatially smoothed using a 3D isotropic Gaussian smoothing kernel (FWHM $=8 \mathrm{~mm}$ ).

\subsubsection{Whole-brain analysis}

We performed first- and second-level statistics using the general linear model framework of SPM5 (Friston et al., 2007). Our $2 \times 2 \times 2 \times 2 \times 2$ design resulted in 32 conditions, hence 32 main regressors, for the statistical analysis of the fMRI data. We used an implicit baseline. In the first-level linear model, we modeled the individual onset times of the photograph (during production trials) or the auditory sentence description (during comprehension trials). We modeled the hemodynamic response function as related to these onsets and set the duration to zero. Separate regressors were included for verbs, photographs during comprehension trials, fillers items, items which were only primes, and incorrect responses. The events of the model were convolved with the canonical hemodynamic response function provided by SPM5. The temporal derivatives were included in the model as well. Furthermore, six motion parameters (realignment parameters: translation along, and rotation around, the $x, y$ and $z$ axes) and two parameters which correct for global intensity fluctuations (compartment signal parameters: white matter and cerebral spinal fluid; Verhagen, Dijkerman, Grol, \& Toni, 2008) were added as regressors. For the second-level random-effects analysis we used the beta-images of the 32 main regressors.

\subsubsection{Region of Interest (ROI) analysis}

We based our regions of interest on independent data by Menenti et al. (2011). They found activations related to syntactic processing in comprehension and in production, centered around MNI coordinates [-52 1022 ] in left IFG (BA 44) and MNI coordinates [-56 -44 4] in left MTG (BA 21). We used a sphere with 8$\mathrm{mm}$ radius around both MNI coordinates. Average time courses were calculated using Marsbar (http://marsbar.sourceforge.net/). We collapsed the data of the two regions in one ROI analysis so that we would be able to investigate potential differences in the response of these two regions. For the ROI analysis at the second level we carried out a repeated-measures ANOVA on the subject contrast values using SPSS; independent variables were region
(LIFG vs. LMTG), syntactic repetition (novel syntax vs. repeated syntax), target structure (active vs. passive voice), modality of the prime (listening vs. speaking), modality of the target (comprehension/listening vs. production/speaking) and verb repetition (novel verb vs. repeated verb).

\section{Results}

\subsection{Whole-brain analysis}

Suprathreshold clusters were defined by thresholding the $\mathrm{SPM}[\mathrm{t}]$ at an uncorrected level corresponding to $P=.001$ and we used the cluster-size as the test-statistic. We report significant clusters with the criterion set at $P<0.05$ corrected for multiple non-independent comparisons.

The following regions showed a repetition suppression effect for repeated versus novel syntactic structures (Fig. 3A): the left inferior frontal gyrus extending into the left insula, and the left precentral gyrus (BA 44/45/47/6), the bilateral supplementary motor area (BA 32), and the bilateral parietal regions (BA 40: inferior parietal and BA 7: precuneus). In addition, we note that there was repetition suppression for repeated versus novel syntactic structures in the left middle temporal gyrus (BA 22) (peak coordinates $[-52-382])$ with voxel-level uncorrected $P<.001$, but this cluster did not reach significance at $P<0.05$ corrected for multiple nonindependent comparisons.

The following regions showed a repetition suppression effect for repeated versus novel verbs (Fig. 3B): the left inferior frontal gyrus extending into the left precentral gyrus (BA 44/45), the left middle temporal gyrus (BA 21), and the left inferior parietal regions (BA 40).

There were no repetition enhancement effects. No regions showed an interaction between the effect of syntactic repetition and the effect of verb repetition. Processing modality of the prime or the target did not affect the strength of syntactic adaptation effects. Also, we did not find any regions showing a three-way interaction between syntactic repetition, verb repetition and any of the other factors we manipulated.

\subsection{ROI analysis}

To maximize detection power, we also investigated possible interactions between syntactic repetition and verb repetition in a ROI analysis. The sensitivity on the whole-brain level may have been insufficient to detect interactions with a between-group factor. ROI analyses allow us to search for potential interactions between syntactic repetition and verb repetition at the highest possible statistical sensitivity. We performed ROI analysis in left IFG and the left MTG (clusters based on Menenti et al., 2011).

An ROI analysis revealed that there was a main effect of the between-subject factor verb repetition $\left(F_{1,46}=51.1, P<.001\right)$ : the ROIs were less activated when the verb was repeated in the target sentence than when the verb was novel. The ROIs were also less activated by sentences with repeated syntactic voice than by sentences with novel syntactic voice $\left(F_{1,46}=12.4, P<.001\right)$. There was less activation for active than for passive sentences $\left(F_{1,46}=45.0, P<\right.$ $.001)$. Furthermore, we obtained main effects of prime modality $\left(F_{1,46}=18.4, P<.001\right)$ and target modality $\left(F_{1,46}=77.6, P<.001\right)$, indicating that the ROIs were less activated during comprehension trials.

Additionally, there was a two-way interaction between syntactic repetition and verb repetition $\left(F_{1,46}=4.02, P<.05\right)$ and a threeway interaction between syntactic repetition, target structure and verb repetition $\left(F_{1,46}=5.90, P<.019\right.$; Fig. 4$)$. Follow-up contrasts showed that under conditions of verb repetition, there was a 


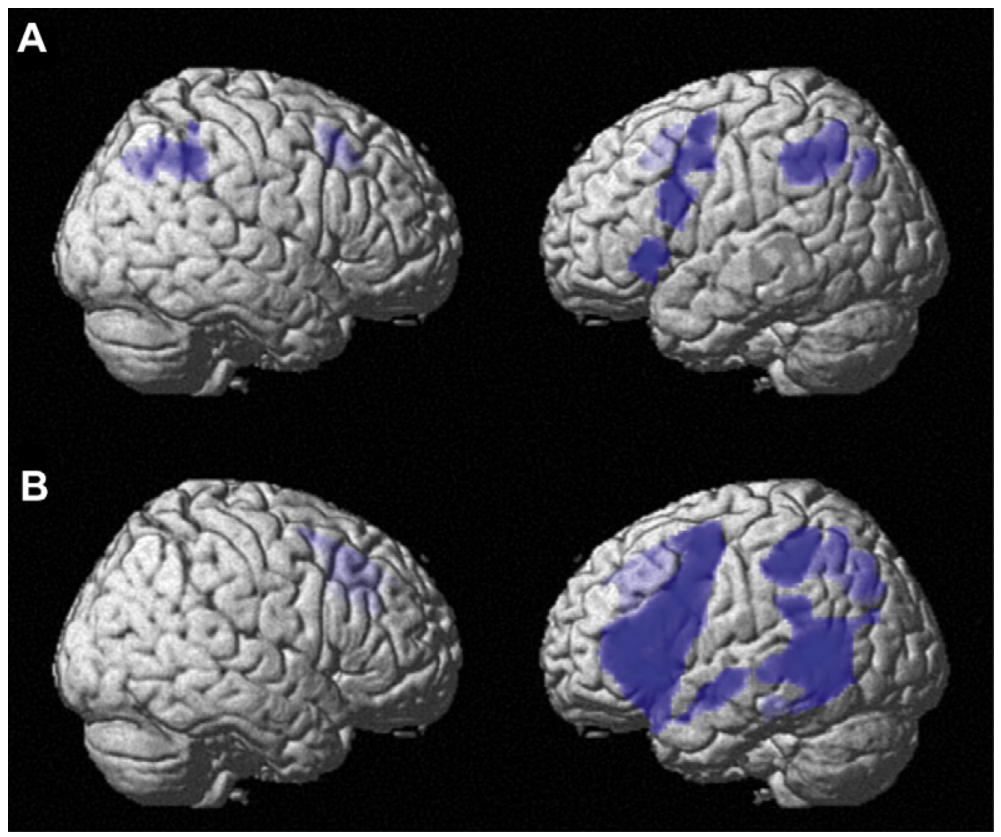

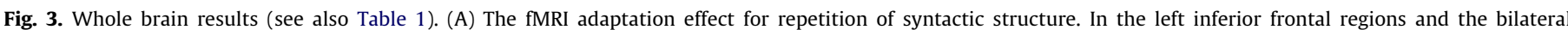

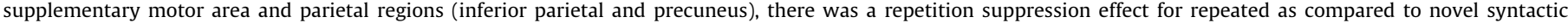

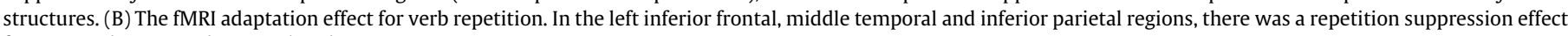
for repeated compared to novel verbs.

significant effect of syntactic repetition $\left(F_{1,23}=15.2, P<.001\right)$ which did not interact with the target structure $\left(F_{1,23}=1.02\right.$, $P>.3$ ). Under conditions without verb repetition, we found no overall effect of syntactic repetition $\left(F_{1,23}=1.16, P>.3\right)$; instead, the effect of syntactic repetition appeared to depend on target structure $\left(F_{1,23}=6.68, P<.017\right)$. More specifically, under conditions without verb repetition, there were syntactic adaptation effects for passive $\left(F_{1,23}=8.44, P<.008\right)$, but not for active sentences $\left(F_{1,23}=.86, P>.3\right)$. Processing modality of the prime and the target did not affect the strength of syntactic adaptation effects. ${ }^{3}$ None of these effects interacted with whether the ROI was left IFG or left MTG, suggesting that there are no differences in the response of these two regions. ${ }^{4}$

\footnotetext{
${ }^{3}$ In Segaert et al. (2012), we showed that, under conditions of verb repetition, there was no interaction between the effect of syntactic repetition (repeated vs. novel syntax of prime and target sentence) and the effect of modality repetition (repeated vs. novel modality between prime and target sentence). The finding by Segaert et al. (2012) that syntactic repetition facilitates syntactic processing in the brain within and across processing modalities to the same extent, indicates that the same neurobiological system subserves syntactic processing in production and comprehension. The new dataset on syntactic repetition effects under conditions of no verb repetition, provided an opportunity to replicate/verify this finding: Again, under conditions without verb repetition, there is no interaction between syntactic repetition and modality repetition $\left(F_{1,23}=.82, P>.3\right)$. Also, there is no interaction between syntactic repetition, target structure and modality repetition $\left(F_{123}=.04, P>.8\right)$. This confirms the conclusion of Segaert et al. (2012) that syntactic repetition facilitates syntactic processing in the brain within and across processing modalities to the same extent. The finding furthermore supports the claim of Segaert et al. (2012) and of the present paper that syntactic processing in production and comprehension relies on similar mechanisms.

${ }^{4}$ We tested whether the difference between the No-Verb-Repetition condition and the Verb-Repetition condition could be due to differences between participant groups instead of differences due to the manipulation of Verb Repetition. To this end, we constructed a factor Reparticipation with 2 levels (participants subjected to the NoVerb-Repetition Condition only vs. participants subjected to the No-Verb-Repetition Condition as well as the Verb-Repetition Condition). We checked whether the effects within the No-Verb-Repetition Condition interacted with the factor Reparticipation: None of the effects did. Difference between the No-Verb-Repetition condition and the Verb-Repetition condition are therefore not due to differences between participant groups.
}

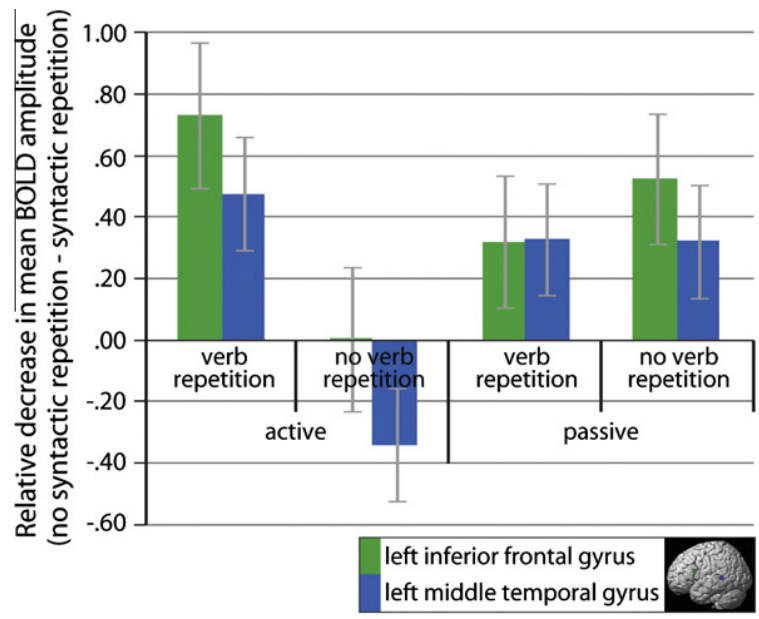

Fig. 4. ROI results. The magnitude of the repetition suppression effect for sentences with a repeated syntactic structure (i.e. sentences with novel syntax minus sentences with repeated syntax) as a function of whether the sentence was active or passive, and whether or not the verb was repeated between consecutive sentences. These repetition suppression effects are depicted separately for two ROI's: the left inferior frontal gyrus and the left middle temporal gyrus.

\section{Discussion}

In the study reported above, we investigated syntactic priming and lexical boost effects on the neuronal activity in brain regions subserving syntactic processing. In our design, the verb and/or the syntactic voice of two consecutive sentences was either repeated or novel. We compared and contrasted the syntactic priming and lexical boost effects in comprehension and production trials. We found repetition suppression in the left IFG and left MTG for sentences with repeated syntax and for sentences with a repeated verb. It must be noted, though, that the effect of syntactic repetition in the left MTG did not reach significance at cluster-level corrected for multiple comparisons. Interestingly, the processing 
Table 1

The effect of syntactic repetition and verb repetition.

\begin{tabular}{|c|c|c|c|c|c|c|c|}
\hline \multirow[t]{2}{*}{ Anatomical label } & \multirow[t]{2}{*}{ BA } & \multicolumn{3}{|c|}{ Global and local maxima } & \multicolumn{2}{|c|}{ Cluster-level } & \multirow{2}{*}{$\begin{array}{l}\text { Voxel-level } \\
\mathrm{Z}\end{array}$} \\
\hline & & $x$ & $y$ & $z$ & $K$ & $\mathrm{P}$ (corr) & \\
\hline \multicolumn{8}{|c|}{ Main effect syntax repetition (no syntactic repetition > syntactic repetition) } \\
\hline $\mathrm{L}$ inf parietal & 40 & -42 & -42 & 38 & 897 & $<.001$ & 5.97 \\
\hline L inf parietal & 40 & -32 & -48 & 36 & & & 5.14 \\
\hline $\mathrm{L}$ inf parietal & 40 & -36 & -48 & 38 & & & 5.11 \\
\hline $\mathrm{R}$ inf parietal & 40 & 36 & -52 & 40 & 506 & $<.001$ & 4.99 \\
\hline $\mathrm{R}$ inf parietal & 40 & 46 & -46 & 42 & & & 3.95 \\
\hline $\mathrm{R}$ inf parietal & 40 & 44 & -44 & 54 & & & 3.30 \\
\hline L precuneus & 7 & -8 & -70 & 40 & 358 & .001 & 4.81 \\
\hline $\mathrm{R}$ precuneus & 7 & 10 & -70 & 40 & & & 3.97 \\
\hline $\mathrm{R}$ precuneus & 7 & 12 & -66 & 38 & & & 3.93 \\
\hline L insula & $13 / 15$ & -28 & 24 & 0 & 479 & $<.001$ & 4.78 \\
\hline L insula & $13 / 15$ & -38 & 22 & 0 & & & 4.06 \\
\hline L inf frontal (pars orbitalis) & 38 & -52 & 24 & -2 & & & 3.72 \\
\hline L precentral & 6 & -36 & 0 & 42 & 839 & $<.001$ & 4.71 \\
\hline L inf frontal (pars triangularis) & 44 & -42 & 12 & 26 & & & 4.11 \\
\hline L inf frontal (pars opercularis) & 44 & -52 & 14 & 18 & & & 4.11 \\
\hline $\mathrm{R}$ mid cingulum & 23 & 2 & -26 & 26 & 180 & .028 & 4.41 \\
\hline $\mathrm{R}$ mid cingulum & 23 & 4 & -22 & 28 & & & 4.30 \\
\hline L supp motor area & 32 & -2 & 14 & 54 & 286 & .003 & 4.13 \\
\hline $\mathrm{R}$ supp motor area & 32 & 6 & 18 & 48 & & & 1.09 \\
\hline L supp motor area & 32 & -4 & 16 & 44 & & & 3.65 \\
\hline \multicolumn{8}{|c|}{ Main effect verb repetition (no verb repetition > verb repetition) } \\
\hline L mid temporal & 21 & -58 & -46 & 2 & 2588 & $<.001$ & 7.55 \\
\hline L mid temporal & 21 & -60 & -52 & 6 & & & 7.51 \\
\hline L mid temporal & 21 & -44 & -50 & 14 & & & 5.36 \\
\hline L precentral & 44 & -48 & 6 & 30 & 5851 & $<.001$ & 7.54 \\
\hline L inf frontal (pars triangularis) & 45 & -50 & 34 & 12 & & & 6.30 \\
\hline L inf frontal (pars triangularis) & 45 & -42 & 30 & 2 & & & 5.85 \\
\hline $\mathrm{L}$ inf parietal & 40 & -46 & -42 & 50 & 1536 & $<.001$ & 5.17 \\
\hline $\mathrm{L}$ inf parietal & 40 & -42 & -38 & 40 & & & 4.63 \\
\hline $\mathrm{L}$ inf parietal & 40 & -56 & -36 & 46 & & & 4.55 \\
\hline L mid temporal & 21 & -56 & -4 & -14 & 296 & .003 & 4.55 \\
\hline $\mathrm{L}$ mid temporal/sup temporal & 22 & -56 & -12 & -6 & & & 4.17 \\
\hline L mid temporal & 21 & -54 & 8 & -22 & & & 3.30 \\
\hline $\begin{array}{l}\text { Interaction syntax repetition } \times v e \\
\text { No significant clusters }\end{array}$ & & & & & & & \\
\hline
\end{tabular}

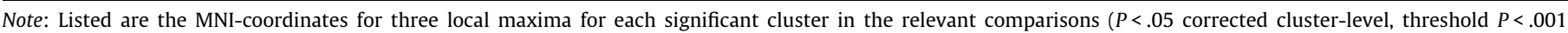
uncorrected voxel-wise). Anatomical labels are derived from the Automated Anatomical Labeling map (Tzourio-Mazoyer et al., 2002) and from Brodmann's atlas.

modality of the sentences (production versus comprehension) did not affect these results. Likewise, whole-brain analysis did not reveal any interactions between syntactic repetition and verb repetition (i.e. a lexical boost). Subsequently, in order to maximize our detection power, we also investigated possible interactions between syntactic repetition and verb repetition in an ROI analysis. The ROI analysis in the left IFG and left MTG revealed the same pattern of results in both regions. For sentences in active voice, there was fMRI adaptation to syntactic repetition when actives had a repeated verb, but no fMRI adaptation to syntactic repetition when actives had a novel verb. For sentences in passive voice, there was no lexical boost: there was fMRI adaptation to syntactic repetition both for passives with a repeated verb and for passives with a novel verb. Once again, the processing modality of the sentences (speaking vs. listening) did not affect these results.

In the behavioral and ERP literature, findings of syntactic priming in comprehension seem to be almost completely dependent on repetition of the head-word (Arai et al., 2007; Branigan et al., 2005; Carminati et al., 2008; Ledoux et al., 2007; Tooley et al., 2009; Traxler \& Tooley, 2007). On the other hand, syntactic priming in production is often observed without lexical repetition (e.g. Branigan et al., 2000; Hartsuiker et al., 2008; Pickering \& Branigan, 1998; Segaert et al., 2011; Wheeldon et al., 2011). This suggests a difference between production and comprehension in the susceptibility to syntactic priming and would support the hypothesis that different (neuro)cognitive processes are involved in sentence production as compared to comprehension. Our present neuroimaging data on the presence versus absence of a lexical boost in syntactic priming do not support this theoretical hypothesis: All adaptation effects were immune to modality differences. Consequently, our findings support views that syntactic priming in the two processing modalities are manifestations of the same, or a similar mechanism (Bock et al., 2007; Pickering \& Branigan, 1999; Pickering \& Garrod, 2004, 2007; Menenti, Pickering, \& Garrod, 2012).

This raises the question why the behavioral and ERP data reported in the literature tend to show a different pattern of syntactic priming and lexical boost effects for the two processing modalities. Previous work has emphasized that it is important to consider the difficulty of the comprehension task when comparing comprehension with production results (Indefrey et al., 2004). During sentence comprehension-as opposed to production-, language users often can bypass full syntactic analysis of the input sentence, due to the availability of semantic, and pragmatic (situational) information. In our study, the production and comprehension tasks both required in-depth processing. Thothathiri and Snedeker (2008a,b) also obtained syntactic priming effects in the absence of verb repetition. Interestingly, the comprehension task in their experiments required in-depth syntactic processing: participants acted out sentences while their eye-movements were recorded. This suggests that detailed syntactic processing is a crucial condition determining whether syntactic repetition alone (i.e., unaccompanied by verb repetition) suffices to yield syntactic priming effects.

An unexpected aspect of our data concerns the absence of lexical boost effects in passive sentences, during production as well as 
comprehension tasks. The presence of a lexical boost in active sentences, also in both modalities, is in line with behavioral studies. The fact that we did not find any syntactic priming for active sentences in the absence of verb repetition does not contradict with the results of earlier production experiments, which typically found syntactic priming effects on syntactic choices for passives but not for actives (experiment 2 and 3 of Bock, 1986; Bock \& Loebell, 1990; Hartsuiker \& Kolk, 1998). Very few production experiments did observe effects for actives, and these were always smaller than for passives (Bernolet, Hartsuiker, \& Pickering, 2009; experiment 1 of Bock, 1986). Also, neuroimaging work has demonstrated that lexical priming influenced the BOLD-response in the left inferior frontal gyrus during comprehension of passive sentences but not during comprehension of active sentences, possibly because the latter requires less syntactic analysis (Keller et al., 2001). Our tentative interpretation of our pattern of results is as follows. Sentences in active voice have a much higher language frequency than, and are strongly preferred over, sentences in passive voice (Segaert et al., 2011). This may have led to a "floor effect": Arguably, syntactic priming of a sentence in the active voice did not reduce neuronal activity to an extent that could be picked up by the BOLD measurements. The repetition suppression for primed actives became noticeable only when syntactic priming of the active voice construction was helped by verb repetition. On the other hand, in the case of syntactically primed sentences in passives voice, we observed repetition suppression not only in the presence but also in the absence of verb repetition. Because passive sentences are much less frequent, a priming benefit in the form of a repetition suppression effect can show up more readily, even in the absence of verb repetition.

Another property of passive voice sentences that may have caused them to be more liable to syntactic priming than active voice sentences, is the fact that they share syntactically important words other than the head verb. The words 'are by' in English ('worden door' in Dutch) are repeated obligatorily. The syntactic skeleton of a passives sentence in English is:

\section{'[NP. . .] be [participle] by [NP...]'}

and in Dutch, it is:

\section{'[NP...] worden door[NP...] [participle]'.}

Hence, the syntactic priming effect we observed for passives may, at least partially, have been helped by repetition of lexical items other than the main verb.

In the behavioral sentence production literature, verb repetition has been found to boost syntactic priming (e.g. Branigan et al., 2000; Corley \& Scheepers, 2002; Hartsuiker et al., 2008; Pickering \& Branigan, 1998; Wheeldon et al., 2011). Why did repetition of the main verb (the participle) in passives not increase the repetition suppression effect in the present study? A possible answer might have to do with an important property of word order in Dutch: As indicated in the syntactic skeleton, the main verb-the participle-is mentioned in Dutch after the two protagonists involved in the depicted action. Hence, the participants could have postponed planning the main verb until after having processed the descriptions of the protagonists. As is well-known, sentence processing often proceeds incrementally (Kempen \& Hoenkamp, 1982, 1987; Levelt, 1989). By postponing, in passive sentences, the planning of the description of the action, the participants could, in effect, spread out processing load over a longer time interval, compared to planning active sentences, where the main verb often must have been planned early on in the sentence. Note that this explanation presupposes the assumption that dealing with the verb contributes more to the activation elicited by syntactic processing than dealing with the NPs governed by the verb. Actually, there is independent fMRI evidence that early placement of main verbs increases the BOLD response in comparison to later placement. den Ouden, Hoogduin, Stowe, and Bastiaanse (2008) found that Dutch activevoice clauses with Subject-Verb-Object order elicited larger BOLD responses in left middle to superior frontal regions than actives with Subject-Object-Verb order. ${ }^{5}$

Our tentative explanation of the differential effect of the lexical boost for actives versus passives could be tested by repeating the present experiment with slightly different Dutch stimulus materials where the active sentences embody a perfectum construction, with the main verbs realized as past-participles (e.g. gewurgd) governed by the active auxiliary heeft ('has'), e.g. De jongen heeft het meisje gewurgd [The boy has strangled the girl]. In active sentences of this type, the verb is placed after both protagonists in the transitive event, just like in passive sentences, e.g. Het meisje werd door de jongen gewurgd [The girl was strangled by the boy]).

\section{Appendix A. Supplementary material}

Supplementary data associated with this article can be found, in the online version, at http://dx.doi.org/10.1016/j.bandl.2012.12. 003.

\section{References}

Arai, M., van Gompel, R. P. G., \& Scheepers, C. (2007). Priming ditransitive structures in comprehension. Cognitive Psychology, 54(3), 218-250.

Bernolet, S., Hartsuiker, R. J., \& Pickering, M. J. (2009). Persistence of emphasis in language production: A cross-linguistic approach. Cognition, 112(2), 300-317.

Bock, K. (1986). Syntactic persistence in language production. Cognitive Psychology, 18(3), 355-387.

Bock, K., Dell, G. S., Chang, F., \& Onishi, K. H. (2007). Persistent structural priming from language comprehension to language production. Cognition, 104(3) 437-458.

Bock, K., \& Griffin, Z. M. (2000). The persistence of structural priming: Transient activation or implicit learning? Journal of Experimental Psychology-General, 129(2), 177-192.

Bock, K., \& Loebell, H. (1990). Framing sentences. Cognition, 35, 1-39.

Branigan, H. P., Pickering, M. J., \& Cleland, A. A. (2000). Syntactic co-ordination in dialogue. Cognition, 75(2), B13-B25.

Branigan, H. P., Pickering, M. J., \& McLean, J. F. (2005). Priming prepositional-phrase attachment during comprehension. Journal of Experimental Psychology-Learning Memory and Cognition, 31(3), 468-481.

Buur, P. F., Poser, B. A., \& Norris, D. G. (2009). A dual echo approach to removing motion artefacts in fMRI time series. NMR in Biomedicine, 22(5), 551-560.

Carminati, M. N., van Gompel, R. P. G., Scheepers, C., \& Arai, M. (2008). Syntactic priming in comprehension: The role of argument order and animacy. Journal of Experimental Psychology-Learning Memory and Cognition, 34(5), 1098-1110.

Chang, F. (2002). Symbolically speaking: A connectionist model of sentence production. Cognitive Science, 26(5), 609-651.

Chang, F., Dell, G. S., \& Bock, K. (2006). Becoming syntactic. Psychological Review 113(2), 234-272.

Chang, F., Dell, G. S., Bock, K., \& Griffin, Z. M. (2000). Structural priming as implicit learning: A comparison of models of sentence production. Journal of Psycholinguistic Research, 29(2), 217-229.

Clark, H. H., \& Chase, W. G. (1972). Process of comparing sentences against pictures Cognitive Psychology, 3(3), 472-517.

Cleland, A. A., \& Pickering, M. J. (2003). The use of lexical and syntactic information in language production: Evidence from the priming of noun-phrase structure. Journal of Memory and Language, 49(2), 214-230.

Cooke, A., Grossman, M., DeVita, C., Gonzalez-Atavales, J., Moore, P., Chen, W., et al. (2006). Large-scale neural network for sentence processing. Brain and Language, 96(1), 14-36.

Corley, M., \& Scheepers, C. (2002). Syntactic priming in English sentence production: Categorical and latency evidence from an internet-based study. Psychonomic Bulletin and Review, 9(1), 126-131.

den Ouden, D. B., Hoogduin, H., Stowe, L. A., \& Bastiaanse, R. (2008). Neural correlates of Dutch verb second in speech production. Brain and Language, 104(2), 122-131

Devauchelle, A. D., Oppenheim, C., Rizzi, L., Dehaene, S., \& Pallier, C. (2009) Sentence syntax and content in the human temporal lobe: An fMRI adaptation

\footnotetext{
${ }^{5}$ den Ouden et al. (2008) interpret the increased BOLD-response for sentences with Subject-Verb-Object order compared to Subject-Object-Verb order as evidence for a syntactic transformation that moves the finite verb from the unmarked/default position into the marked verb-second position.
} 
study in auditory and visual modalities. Journal of Cognitive Neuroscience, 21(5), 1000-1012.

Embick, D., Marantz, A., Miyashita, Y., O’Neil, W., \& Sakai, K. L. (2000). A syntactic specialization for Broca's area. Proceedings of the National Academy of Sciences of the United States of America, 97(11), 6150-6154.

Ferreira, V. S., \& Bock, K. (2006). The functions of structural priming. Language and Cognitive Processes, 21(7-8), 1011-1029.

Fiebach, C. J., Schlesewsky, M., Lohmann, G., von Cramon, D. Y., \& Friederici, A. D. (2005). Revisiting the role of Broca's area in sentence processing: Syntactic integration versus syntactic working memory. Human Brain Mapping, 24(2), 79-91.

Friston, K. J., Ashburner, J. T., Kiebel, S. J., Nichols, T. E., \& Penny, W. D. (2007) Statistical parametric mapping: The analysis of functional brain images. San Diego (CA): Academic Press.

Hagoort, P. (2003). How the brain solves the binding problem for language: neurocomputational model of syntactic processing. Neuroimage, 20, S18-S29.

Hagoort, P. (2005). On Broca, brain, and binding: A new framework. Trends in Cognitive Sciences, 9(9), 416-423.

Haller, S., Radue, E. W., Erb, M., Grodd, W., \& Kircher, T. (2005). Overt sentence production in event-related fMRI. Neuropsychologia, 43(5), 807-814

Hartsuiker, R. J., Bernolet, S., Schoonbaert, S., Speybroeck, S., \& Vanderelst, D. (2008). Syntactic priming persists while the lexical boost decays: Evidence from written and spoken dialogue. Journal of Memory and Language, 58(2), 214-238.

Hartsuiker, R. J., \& Kolk, H. H. J. (1998). Syntactic persistence in Dutch. Language and Speech, 41, 143-184.

Henson, R. (2003). Neuroimaging studies of priming. Progress in Neurobiology, 70(1) 53-81.

Indefrey, P., Brown, C. M., Hellwig, F., Amunts, K., Herzog, H., Seitz, R. J., et al. (2001). A neural correlate of syntactic encoding during speech production. Proceedings of the National Academy of Sciences of the United States of America, 98(10), 5933-5936.

Indefrey, P. (2012a). Hemodynamic studies of syntactic processing. In M. Faust (Ed.), Handbook of the neuropsychology of language. Language processing in the brain: Basic science (Vol. 1, pp. 209-228). Malden, MA: Wiley-Blackwell.

Indefrey, P., Hellwig, F., Herzog, H., Seitz, R. J., \& Hagoort, P. (2004). Neural responses to the production and comprehension of syntax in identical utterances. Brain and Language, 89(2), 312-319.

Indefrey, P. (2012b). Neurobiology of syntax. In P. C. Hogan (Ed.), The Cambridge encyclopedia of the language sciences (pp. 835-838). Cambridge, New York: Cambridge University Press.

Keller, T. A., Carpenter, P. A., \& Just, M. A. (2001). The neural bases of sentence comprehension: A fMRI examination of syntactic and lexical processing. Cerebral Cortex, 11(3), 223-237.

Kempen, G., \& Hoenkamp, E. (1982). Incremental sentence generation: Implications for the structure of a syntactic processor. Paper presented at the proceedings of the ninth international conference on computational linguistics, Prague, July 1982 (COLING82).

Kempen, G., \& Hoenkamp, E. (1987). An incremental procedural grammar for sentence formulation. Cognitive Science, 11(2), 201-258.

Kempen, G. (1977). Conceptualizing and formulating in sentence production. In S Rosenberg (Ed.), Sentence production: Developments in research and theory (pp. 259-274). Hillsdale, NJ: Erlbaum.

Knoeferle, P., Urbach, T. P., \& Kutas, M. (2011). Comprehending how visual context influences incremental sentence processing: Insights from ERPs and picturesentence verification. Psychophysiology, 48(4), 495-506.

Ledoux, K., Traxler, M. J., \& Swaab, T. Y. (2007). Syntactic priming in comprehension - Evidence from event-related potentials. Psychological Science, 18(2), 135-143.

Levelt, W. J. M. (1989). Speaking: From intention to articulation. Cambridge, MA: MIT Press.

Menenti, L., Gierhan, S., Segaert, K., \& Hagoort, P. (2011). Shared language: Overlap and segregation of the neuronal infrastructure for speaking and listening revealed by fMRI. Psychological Science, 22, 1173-1182.

Menenti, L., Segaert, K., \& Hagoort, P. (2012). The neuronal infrastructure of speaking. Brain and Language, 122, 71-80.

Menenti, L., Pickering, M. J., \& Garrod, S. C. (2012). Toward a neural basis of interactive alignment in conversation. Frontiers in Human Neuroscience, 6.

Newman, S. D., Ratliff, K., Muratore, T., \& Burns, T. (2009). The effect of lexical priming on sentence comprehension: An fMRI study. Brain Research, 1285, 99-108.

Ni, W., Constable, R. T., Mencl, W. E., Pugh, K. R., Fulbright, R. K., Shaywitz, S. E., et al (2000). An event-related neuroimaging study distinguishing form and content in sentence processing. Journal of Cognitive Neuroscience, 12(1), 120-133.
Noppeney, U., \& Price, C. J. (2004). An fMRI study of syntactic adaptation. Journal of Cognitive Neuroscience, 16(4), 702-713.

Peck, K. K., Wierenga, C. E., Moore, A. B., Maher, L. M., Gopinath, K., Gaiefsky, M., et al. (2004). Comparison of baseline conditions to investigate syntactic production using functional magnetic resonance imaging. Neuroimage, 23(1), 104-110.

Pickering, M. J., \& Branigan, H. P. (1998). The representation of verbs: Evidence from syntactic priming in language production. Journal of Memory and Language, 39(4), 633-651.

Pickering, M. J., \& Branigan, H. P. (1999). Syntactic priming in language production. Trends in Cognitive Sciences, 3(4), 136-141.

Pickering, M. J., \& Ferreira, V. S. (2008). Structural priming: A critical review. Psychological Bulletin, 134(3), 427-459.

Pickering, M. J., \& Garrod, S. (2004). Toward a mechanistic psychology of dialogue. Behavioral and Brain Sciences, 27(2), 169-+

Pickering, M. J., \& Garrod, S. (2007). Do people use language production to make predictions during comprehension? Trends in Cognitive Sciences, 11(3), 105-110.

Poser, B. A., Versluis, M. J., Hoogduin, J. M., \& Norris, D. G. (2006). BOLD contrast sensitivity enhancement and artifact reduction with multiecho EPI: Parallelacquired inhomogeneity-desensitized fMRI. Magnetic Resonance in Medicine, 55(6), 1227-1235.

Segaert, K., Weber, K., de Lange, F. P., Petersson, K. M., \& Hagoort, P. (2013). The suppression of repetition enhancement: A review of fMRI studies. Neuropsychologia, 51, 59-66.

Segaert, K., Menenti, L., Weber, K., \& Hagoort, P. (2011). A paradox of syntactic priming. Why response tendencies show priming for passives and response latencies show priming for actives. PLoS ONE, 6(10), e24209. doi:24210.21371/ journal.pone.0024209.

Segaert, K., Menenti, L., Weber, K., Petersson, K. M., \& Hagoort, P. (2012). Shared syntax in language production and language comprehension - An fMRI study. Cerebral Cortex, 22(7), 1662-1670.

Smith, M., \& Wheeldon, L. (2001). Syntactic priming in spoken sentence production - an online study. Cognition, 78(2), 123-164.

Snijders, T. M., Vosse, T., Kempen, G., Van Berkum, J. J. A., Petersson, K. M., \& Hagoort, P. (2009). Retrieval and unification of syntactic structure in sentence comprehension: An fMRI Study using word-category ambiguity. Cerebral Cortex, 19(7), 1493-1503.

Thothathiri, M., \& Snedeker, J. (2008a). Give and take: Syntactic priming during spoken language comprehension. Cognition, 108(1), 51-68.

Thothathiri, M., \& Snedeker, J. (2008b). Syntactic priming during language comprehension in three- and 4-year-old children. Journal of Memory and Language, 58(2), 188-213.

Tooley, K. M., Traxler, M. J., \& Swaab, T. Y. (2009). Electrophysiological and behavioral evidence of syntactic priming in sentence comprehension. Journal of Experimental Psychology-Learning Memory and Cognition, 35(1), 19-45.

Traxler, M. J. (2008). Lexically independent priming in online sentence comprehension. Psychonomic Bulletin and Review, 15(1), 149-155.

Traxler, M. J., \& Tooley, K. M. (2007). Lexical mediation and context effects in sentence processing. Brain Research, 1146, 59-74.

Traxler, M. J., \& Tooley, K. M. (2008). Priming in sentence comprehension: Strategic or syntactic? Language and Cognitive Processes, 23(5), 609-645.

Tzourio-Mazoyer, N., Landeau, B., Papathanassiou, D., Crivello, F., Etard, O., Delcroix, $\mathrm{N}$. et al. (2002). Automated anatomical labeling of activations in SPM using a macroscopic anatomical parcellation of the MNI MRI single-subject brain. Neuroimage, 15, 273-289.

Verhagen, L., Dijkerman, H. C., Grol, M. J., \& Toni, I. (2008). Perceptuo-motor interactions during prehension movements. Journal of Neuroscience, 28(18), 4726-4735.

Vigneau, M., Beaucousin, V., Herve, P. Y., Duffau, H., Crivello, F., Houde, O., et al. (2006). Meta-analyzing left hemisphere language areas: Phonology, semantics, and sentence processing. Neuroimage, 30(4), 1414-1432.

Weber, K., \& Indefrey, P. (2009). Syntactic priming in German-English bilinguals during sentence comprehension. Neuroimage, 46(4), 1164-1172.

Wheeldon, L. R., \& Smith, M. C. (2003). Phrase structure priming: A short-lived effect. Language and Cognitive Processes, 18(4), 431-442.

Wheeldon, L. R., Smith, M. C., \& Apperly, I. A. (2011). Repeating words in sentences: Effects of sentence structure. Journal of Experimental Psychology-Learning Memory and Cognition, 37(5), 1051-1064. 